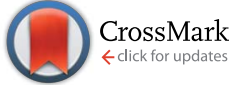

Cite this: RSC Adv., 2016, 6, 541

\title{
Trace metal profiles in mosses and lichens from the high-altitude Tibetan Plateau
}

\author{
Jun-juan Shao, ${ }^{a}$ Jian-bo Shi, ${ }^{* a b}$ Bu Duo, ${ }^{c}$ Cheng-bin Liu, ${ }^{a}$ Yan Gao, ${ }^{a}$ Jian-jie Fu, ${ }^{a}$ \\ Rui-qiang Yang, ${ }^{a}$ Yong Cai ${ }^{a b}$ and Gui-bin Jiang ${ }^{a}$
}

The high-altitude Tibetan Plateau plays a significant role in the distribution and transport of contaminants, but there are limited studies on the levels, patterns and distributions of trace metals in this typical region. In this work, the accumulation and distribution profiles of trace metals in mosses and lichens collected from the Tibetan Plateau were particularly focused on because they are geographically widespread plants and absorb most nutrients from the atmosphere. The results showed that the concentrations of $\mathrm{Cr}, \mathrm{Mn}, \mathrm{Co}$, $\mathrm{Ni}, \mathrm{Cu}, \mathrm{As}$ and $\mathrm{Pb}$ in mosses were significantly higher than those in lichens collected from the same sites, indicating that mosses and lichens from the Tibetan Plateau had different abilities for accumulating these metals. Significantly positive correlations were found among the concentrations of trace metals (such as $\mathrm{Cr}-\mathrm{Co}-\mathrm{Ni}$ and $\mathrm{Cu}-\mathrm{As}-\mathrm{Pb}, \mathrm{p}<0.05)$ in both mosses and lichens. The spatial distribution of most determined metals in mosses and lichens displayed a decreasing trend from south to north and from west to east. The contents of $\mathrm{Mn}, \mathrm{Co}, \mathrm{Ni}, \mathrm{Cu}, \mathrm{As}, \mathrm{Cd}$ and $\mathrm{Pb}$ in mosses increased with the ascending altitudes of the sampling sites, implying the influence and mountain trapping of the Tibetan Plateau on these trace metals.

Received 20th October 2015 Accepted 14th December 2015

DOI: $10.1039 / \mathrm{c} 5 \mathrm{ra} 21920 \mathrm{e}$

www.rsc.org/advances detected in wild fish collected from several lakes and Lhasa River in the Tibetan Plateau. ${ }^{8}$ Crustal enrichment factor (EF) and the backward air mass trajectory analysis indicated that some trace metals ( $\mathrm{Cr}, \mathrm{Ni}, \mathrm{Cu}, \mathrm{Zn}, \mathrm{As})$ in aerosols from the Nam Co region of the Tibetan Plateau were transported atmospherically to this region over long distance and might be from South Asia. ${ }^{12}$ The high concentration and EF values of trace metals in sediments from Ximen Co Lake on the eastern Tibetan Plateau also showed that the trace metals could be transported over long distance under the influence of southwest monsoon. ${ }^{\mathbf{1 3}}$ Furthermore, relatively high levels of some persistent organic pollutants (POPs) have also been found in alpine fish from the Tibetan Plateau including hexabromocyclododecane, ${ }^{7}$ organochlorine pesticides ${ }^{8}$ and so on. Nevertheless, the previous work were mainly focused on a specific area or ecosystem in the Tibetan Plateau. Therefore, the data is insufficient due to the vast of the Tibetan Plateau, and more studies are needed to understand the distribution patterns and profiles of trace metals over the Tibetan Plateau and to provide reference concentrations for this vast and sparse plateau for future evaluation on environmental changes.

Mosses and lichens are good bioindicators of trace metals and have been widely used to study the regional or global distribution and source of trace metals. ${ }^{14-19}$ The concentrations of $\mathrm{Hg}$ in lichens have been found decreased with distance away from the chloralkali plan in Grenoble of France..$^{20}$ The V, Co, Ni, Cu and $\mathrm{Zn}$ in lichens from Argentina were found mainly from urban emissions. ${ }^{21}$ In high-altitude and harsh Tibetan Plateau, mosses and
${ }^{a}$ State Key Laboratory of Environmental Chemistry and Ecotoxicology, Research Center for Eco-Environmental Sciences, Chinese Academy of Sciences, Beijing 100085, China. E-mail: jbshi@rcees.ac.cn; Fax: +86-10-62849129; Tel: +86-10-62849129

${ }^{b}$ Institute of Environment and Health, Jianghan University, Wuhan 430056, China ${ }^{c}$ Science Faculty, Tibet University, Lhasa 850000, China 
lichens distribute widely and have enough abundance, which make the large-scale and repetitious studies are achievable. However, because of the harsh environment and the complex geographical condition, there is still no report on the trace metals in mosses and lichens from the Tibetan Plateau up to now.

The aim of this work was to characterize and compare the patterns and concentrations of 8 elements (Cr, Mn, Co, Ni, Cu, As, $\mathrm{Cd}$ and $\mathrm{Pb}$ ) in moss and lichen samples. This work will provide a basis for future studies about trace metals in the Tibetan Plateau.

\section{Materials and methods}

\subsection{Sample collection}

The map of the study area is shown in Fig. 1. A total of 124 mosses (Bryopsida) and 30 lichens (Usnealongissima Ach.) were collected from the Tibetan Plateau in June of 2010, 2011 and 2012. Mosses and lichens were collected along the National highway no. 318 and the provincial road no. 306. In each site, lichens were taken from pine trees and mosses were crustose. The samples were collected using a stainless steel spade. All moss and lichen samples were transported to the laboratory as soon as possible. The green shoots of mosses and the outermost portion of the lichens were rinsed with deionized water, freezedried, ground and then kept at $-20{ }^{\circ} \mathrm{C}$ until analyzing.

\subsection{Determination of trace metals}

For mosses and lichens, $0.05-0.1 \mathrm{~g}$ sample was weighed into a polytetrafluoro ethylene digestion vessel. Then, $3 \mathrm{~mL}$ concentrated nitric acid (65\%, analytical grade, Merck) and
$3 \mathrm{~mL}$ hydrogen peroxide (guaranteed reagent, Beijing Chemical Company) was added. The vessels were heated to $50{ }^{\circ} \mathrm{C}$ for 30 minutes ( $\mathrm{min}$ ) to predigest. Afterwards, the vessels were sealed and transferred to a microwave digestion system (MARSX, CEM, USA). The digestion program was set up as follows: ramp to $140{ }^{\circ} \mathrm{C}$ in $10 \mathrm{~min}$ and hold for $10 \mathrm{~min}$, ramp to $160{ }^{\circ} \mathrm{C}$ in $10 \mathrm{~min}$ and hold for $10 \mathrm{~min}$, ramp to $180^{\circ} \mathrm{C}$ in $10 \mathrm{~min}$ and hold for $30 \mathrm{~min}$. After cooling down to room temperature, the digestion solution was diluted with deionized water (18.2 $\mathrm{M} \Omega$; Milli-Q, Bedford, USA) and then centrifuged at $3000 \mathrm{rpm}$ for $20 \mathrm{~min}$. The samples were analyzed with an inductively coupled plasma mass spectrometer (ICP-MS, Thermo Fisher iCAP Q, USA) for total concentrations of $\mathrm{Cr}, \mathrm{Mn}, \mathrm{Co}, \mathrm{Ni}, \mathrm{Cu}, \mathrm{As}$, $\mathrm{Cd}$ and $\mathrm{Pb}$. High abundance and low interference mass number $\left({ }^{52} \mathrm{Cr},{ }^{55} \mathrm{Mn},{ }^{59} \mathrm{Co},{ }^{60} \mathrm{Ni},{ }^{63} \mathrm{Cu},{ }^{75} \mathrm{As},{ }^{111} \mathrm{Cd},{ }^{208} \mathrm{~Pb}\right)$ were selected. Kinetic energy discrimination (KED) model was applied to eliminate potential interferences. ${ }^{45} \mathrm{Sc},{ }^{89} \mathrm{Y},{ }^{103} \mathrm{Rh},{ }^{115} \mathrm{In},{ }^{159} \mathrm{~Tb}$, ${ }^{165} \mathrm{Ho}$ and ${ }^{209} \mathrm{Bi}$ were used as internal standard to evaluate the stability of the instrument.

\subsection{Quality assurance/quality control (QA/QC)}

For the analytical quality control, reagent and method blanks, certified reference materials (CRMs) and sample replicates were conducted in each batch digestion. The reagent and method blanks were low. For all CRMs used, the found values of all elements were in good agreement with the certified values (Table 1). The relative standard deviations (RSDs) of triplicate samples analysis were in the range of $0.34-9.98 \%$, suggesting that the proposed method was reliable.

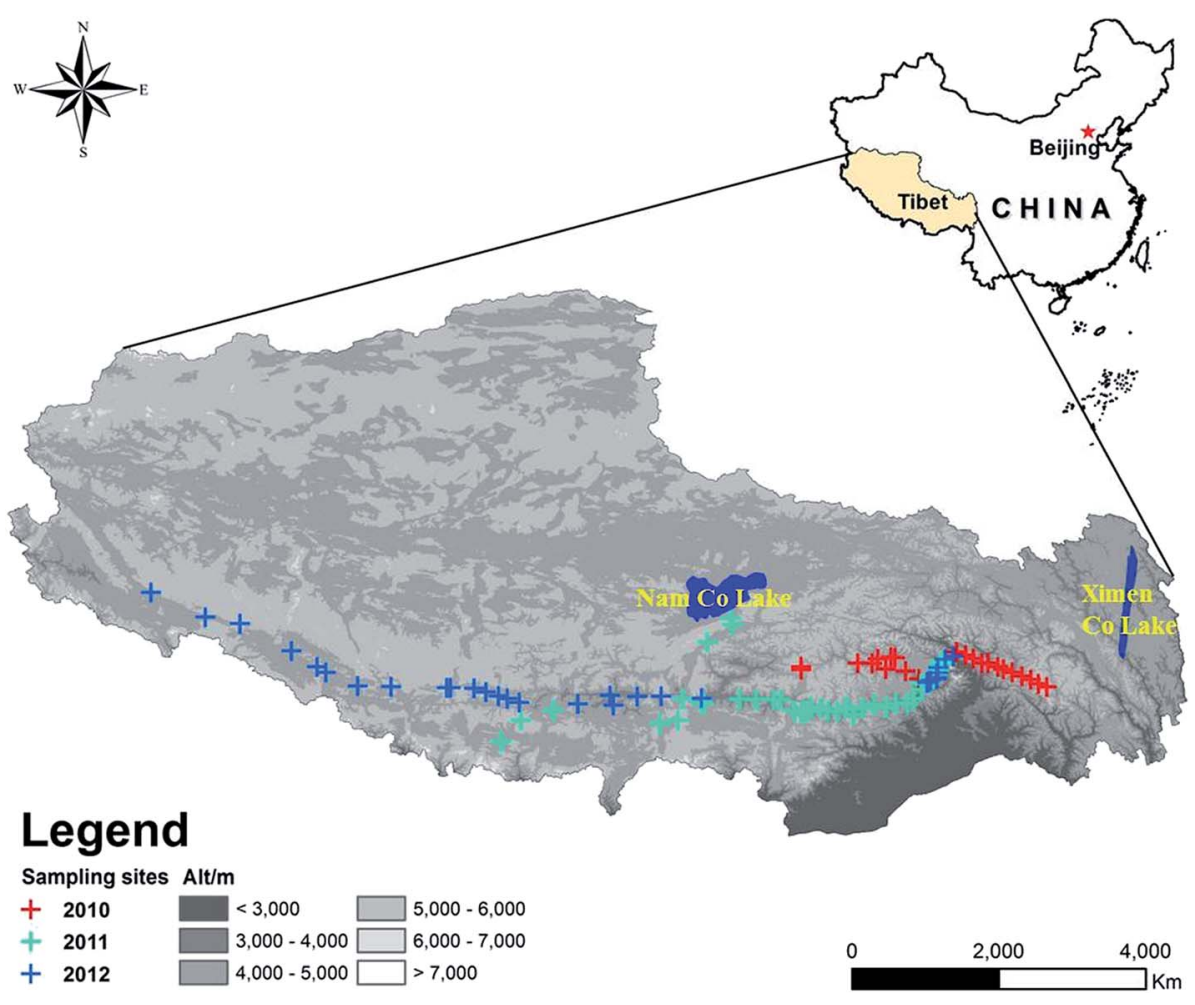

Fig. 1 The map of the study area. 
Table 1 Results of trace metals in certified reference materials (CRMs) $(n=5)$

\begin{tabular}{|c|c|c|c|c|c|c|}
\hline & \multicolumn{3}{|l|}{ GBW08501 (peach) } & \multicolumn{3}{|l|}{ DORM-3 (fish) } \\
\hline & Certified $\left(\mu g g^{-1}\right)$ & Found $\left(\mu g g^{-1}\right)$ & Recovery (\%) & Certified $\left(\mu g g^{-1}\right)$ & Found $\left(\mu g g^{-1}\right)$ & Recovery (\%) \\
\hline $\mathrm{Cr}$ & $0.94 \pm 0.07$ & $0.77 \pm 0.07$ & $82.1 \pm 7.4$ & $1.89 \pm 0.17$ & $2.01 \pm 0.09$ & $106.6 \pm 4.8$ \\
\hline Mn & $75.4 \pm 2.7$ & $73.07 \pm 3.77$ & $96.9 \pm 5.0$ & - & $3.56 \pm 0.24$ & - \\
\hline Co & 0.25 & $0.22 \pm 0.02$ & $87.2 \pm 8.0$ & - & $0.28 \pm 0.03$ & - \\
\hline $\mathrm{Ni}$ & - & $1.03 \pm 0.06$ & - & $1.28 \pm 0.24$ & $1.30 \pm 0.11$ & $101.2 \pm 8.6$ \\
\hline $\mathrm{Cu}$ & $10.4 \pm 0.8$ & $9.76 \pm 1.02$ & $93.9 \pm 9.8$ & $15.5 \pm 0.63$ & $16.7 \pm 1.08$ & $107.5 \pm 7.0$ \\
\hline As & $0.34 \pm 0.03$ & $0.35 \pm 0.03$ & $102.7 \pm 8.8$ & $6.88 \pm 0.30$ & $6.86 \pm 0.32$ & $99.74 \pm 4.7$ \\
\hline $\mathrm{Cd}$ & $0.018 \pm 0.004$ & $0.019 \pm 0.0003$ & $108.0 \pm 1.7$ & $0.290 \pm 0.020$ & $0.298 \pm 0.01$ & $103.0 \pm 3.4$ \\
\hline $\mathrm{Pb}$ & $0.99 \pm 0.04$ & $0.95 \pm 0.06$ & $96.4 \pm 6.1$ & $0.395 \pm 0.050$ & $0.409 \pm 0.018$ & $103.6 \pm 4.6$ \\
\hline
\end{tabular}

\subsection{Statistical analysis}

Multiple statistical analyses methods were used with SPSS 20.0 to find the relationships among these trace metals in mosses and lichens. Paired samples test was applied to compare the difference in trace metals levels in mosses and lichens from the same sampling sites. Spearman correlation was applied to find the correlation between the trace metals concentrations in mosses and lichens and the correlation between trace metals concentrations and the altitudes, latitudes and longitudes of the sampling sites.

\section{Results and discussion}

\subsection{Concentrations of trace metals in mosses and lichens}

The average concentrations and ranges of measured 8 elements in moss and lichen samples are listed in Table 2. The levels and patterns of detected trace metals in mosses and lichens were different. The averages for the trace metals in mosses were in the order of $\mathrm{Mn}>\mathrm{Cr}>\mathrm{Ni}>\mathrm{Cu}>\mathrm{Pb}>\mathrm{As}>\mathrm{Co}>\mathrm{Cd}$, while the order for lichens was $\mathrm{Mn}>\mathrm{Cr}>\mathrm{Cu}>\mathrm{Ni}>\mathrm{Pb}>\mathrm{As}>\mathrm{Co}>\mathrm{Cd}$. $\mathrm{Cr}$ and $\mathrm{Mn}$ were the major elements detected in mosses and lichens from Tibetan Plateau. $\mathrm{Cr}, \mathrm{Mn}, \mathrm{Co}, \mathrm{Ni}, \mathrm{Cu}, \mathrm{As}$ and $\mathrm{Pb}$ were detected in all moss and lichen samples. Cd was detected in 107 mosses out of the total 124 samples and 28 lichens out of the total 30 samples (the detection limit: $6.8 \mathrm{ng}^{-1}$ ).
In this study, 25 pair mosses and lichens were collected from the same sampling sites. Paired samples test was applied to compare the ability of mosses and lichens to enrich trace metals. The results showed that there were significantly different between the trace metals contents (except Cd) in mosses and lichens. Mosses had significantly higher concentrations of $\mathrm{Cr}, \mathrm{Mn}, \mathrm{Co}, \mathrm{Ni}, \mathrm{Cu}$, As and $\mathrm{Pb}(p<0.01$ for all) than lichens (Fig. 2). These trace metals concentrations in mosses were 2 to 4 times of those in lichens, indicating the significant differences in accumulation efficiency for $\mathrm{Cr}, \mathrm{Mn}, \mathrm{Co}, \mathrm{Ni}, \mathrm{Cu}, \mathrm{As}$ and $\mathrm{Pb}$ between mosses and lichens in the Tibetan Plateau.

Compared with the trace metals concentrations in mosses from other remote areas such as Arctic and Antarctic, all mosses samples were probably contaminated with different levels of trace metals. For mosses, the concentrations of $\mathrm{Cr}$ and As were about 10 folds higher than those from Arctic $^{22,23}$ and Antarctic, ${ }^{24}$ and the contents of $\mathrm{Mn}, \mathrm{Co}, \mathrm{Ni}, \mathrm{Cu}$ and $\mathrm{Pb}$ were about twice higher than those from Arctic $^{22,23}$ and Antarctic. ${ }^{24}$ The levels of $\mathrm{Cd}$ in mosses collected in this work were comparable to those from Arctic $^{22,23}$ and Antarctic. ${ }^{24}$ On the contrary, the concentrations of $\mathrm{Co}, \mathrm{Ni}, \mathrm{Cu}, \mathrm{Cd}$ and $\mathrm{Pb}$ in lichens from the Tibetan Plateau were comparable to those from Arctic ${ }^{22,23}$ and Antarctic. ${ }^{24}$ Only the concentrations of $\mathrm{Cr}$ and $\mathrm{Mn}$ in lichens collected in this study were about 10 folds higher than those in lichens from Antarctic ${ }^{24}$ and twice higher than those from Arctic. $^{22,23}$ The relatively high concentrations of trace metals in mosses and lichens from

Table 2 Comparison of trace metals in mosses and lichens from remote areas $\left(\mu \mathrm{g} \mathrm{g}^{-1}, \mathrm{dw}\right)$

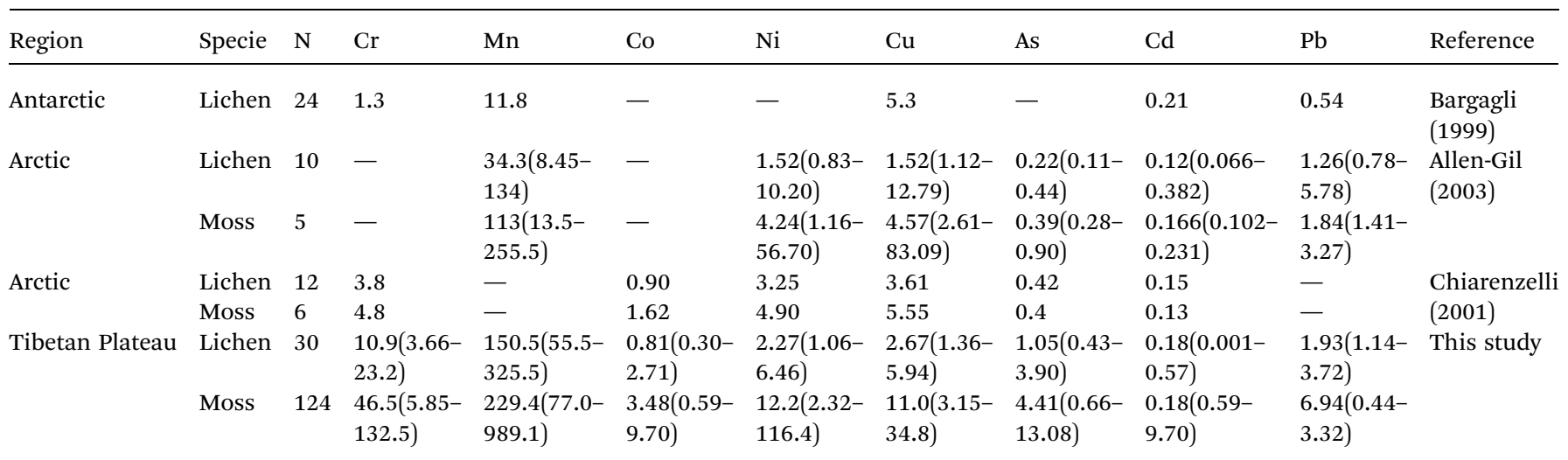




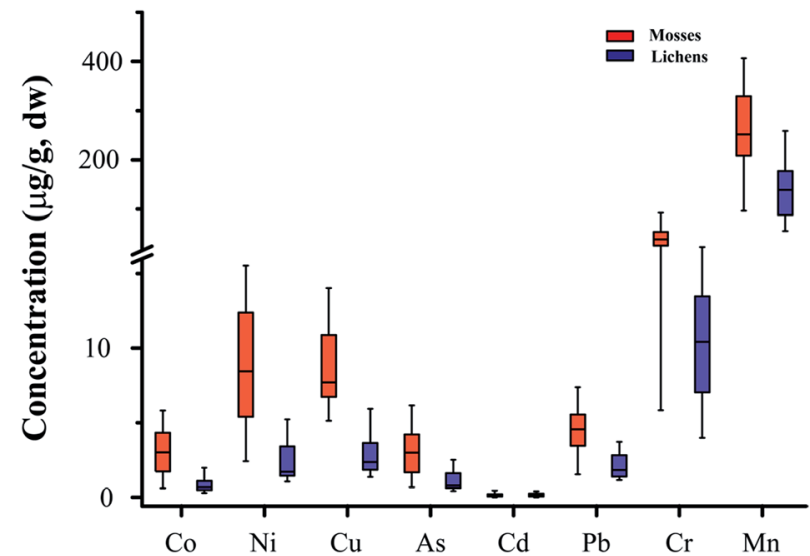

Fig. 2 Comparison of concentrations of trace metals in mosses and lichens from the same sampling sites (red: mosses; blue: lichens).

Tibetan Plateau could be attributed to the long range atmosphere transport and high wet deposition in the high-altitude Tibetan Plateau. The backward air mass trajectory analysis has showed that the trace metals in aerosols from the Nam Co Lake and in sediments from Ximen Co Lake in the Tibetan Plateau were long distance transported atmospherically from the South Asia. ${ }^{12,13}$ Meanwhile, the more frequent wet precipitation in the high-altitude Tibetan Plateau could increase the deposition of trace metals and their accumulation in mosses and lichens.

\subsection{The correlation analysis and principal component analysis (PCA)}

For mosses and lichens, the significant correlations among trace metals suggest the common sources of the related elements. ${ }^{25,26}$ Results of correlation analysis between these trace metals contents were summarized in Table 3. On the whole, there were significant correlations among concentrations of trace metals in adjacent main group or subgroup in periodic table of elements. In mosses, $\mathrm{Mn}, \mathrm{Co}, \mathrm{Ni}$ and $\mathrm{Cu}$ located in the adjacent group of the periodic table of elements had significant correlation $(p<0.01)$. In lichens, there were significant correlations among $\mathrm{Co}, \mathrm{Ni}$ and $\mathrm{Cu}$ as well. Besides the significant correlation among these elements located in the adjacent position of the periodic table of elements, the correlations among thiophile element $(\mathrm{Cu}-\mathrm{As}-\mathrm{Pb})$ in mosses and lichens were also significant. The correlations among these anthropogenic elements may be attributed to vehicle emissions. ${ }^{25}$

Principal component analysis (PCA) was performed to analyze the distribution of trace metals in mosses and lichens from the Tibetan Plateau (Fig. 3). The original metal concentrations in mosses and lichens were normalized respectively before the PCA using the following formula: ${ }^{27,28}$
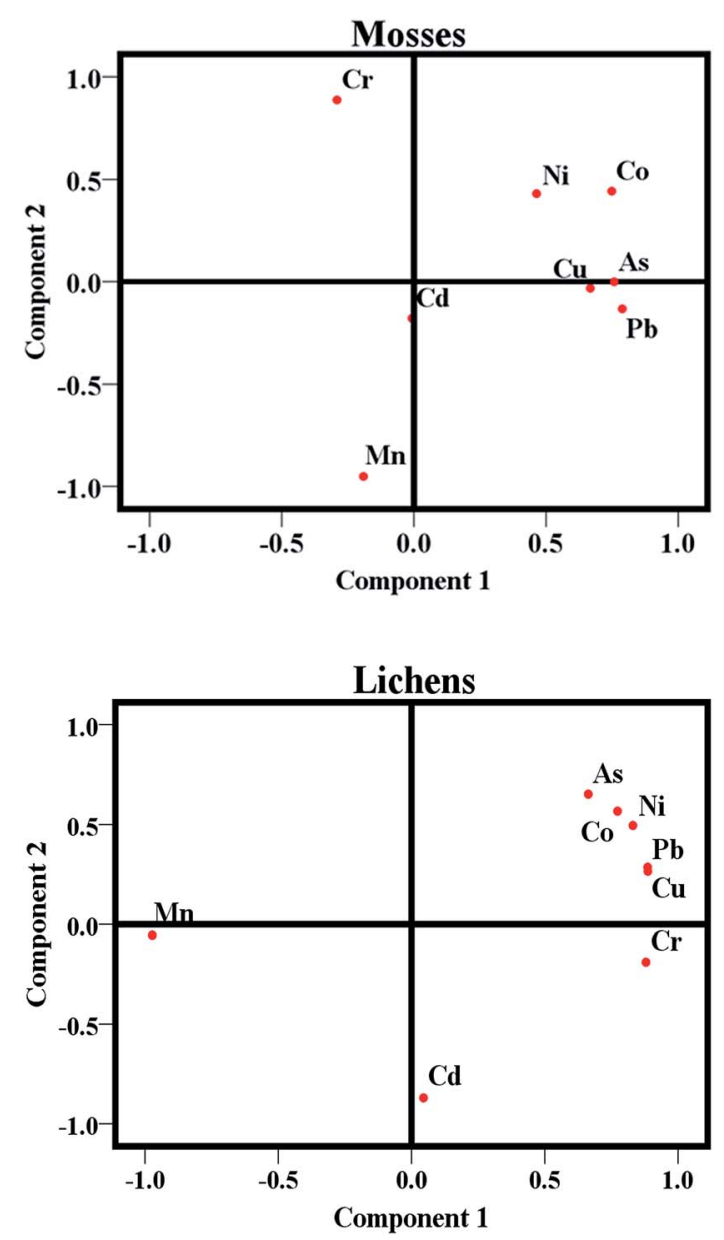

Fig. 3 The results of factor analysis.

Table 3 Correlation matrixes of the concentrations of trace metals in mosses and lichens

\begin{tabular}{|c|c|c|c|c|c|c|c|c|c|c|c|c|c|c|c|c|}
\hline & \multicolumn{8}{|l|}{ Mosses } & \multicolumn{8}{|l|}{ Lichens } \\
\hline & $\mathrm{Cr}$ & $\mathrm{Mn}$ & Co & $\mathrm{Ni}$ & $\mathrm{Cu}$ & As & $\mathrm{Cd}$ & $\mathrm{Pb}$ & $\mathrm{Cr}$ & Mn & Co & $\mathrm{Ni}$ & $\mathrm{Cu}$ & As & $\mathrm{Cd}$ & $\mathrm{Pb}$ \\
\hline $\mathrm{Cr}$ & 1.000 & & & & & & & & 1.000 & & & & & & & \\
\hline Mn & -0.123 & 1.000 & & & & & & & -0.284 & 1.000 & & & & & & \\
\hline Co & $0.216^{b}$ & $0.238^{a}$ & 1.000 & & & & & & $0.648^{a}$ & -0.232 & 1.000 & & & & & \\
\hline $\mathrm{Ni}$ & $0.187^{b}$ & $0.294^{a}$ & $0.870^{a}$ & 1.000 & & & & & $0.700^{a}$ & -0.070 & $\mathbf{0 . 8 8 7 ^ { a }}$ & 1.000 & & & & \\
\hline $\mathrm{Cu}$ & -0.072 & $0.273^{a}$ & $0.699^{a}$ & $0.711^{a}$ & 1.000 & & & & $0.527^{a}$ & 0.002 & $0.707^{a}$ & $0.699^{a}$ & 1.000 & & & \\
\hline As & 0.063 & $0.238^{a}$ & $0.629^{a}$ & $0.683^{a}$ & $0.545^{a}$ & 1.000 & & & $0.451^{b}$ & 0.040 & $0.783^{a}$ & $0.782^{a}$ & $0.624^{a}$ & 1.000 & & \\
\hline $\mathrm{Cd}$ & $-0.242^{b}$ & 0.102 & $-0.266^{a}$ & -0.188 & 0.003 & $-0.319^{a}$ & 1.000 & & -0.198 & 0.288 & $-0.377^{b}$ & -0.331 & 0.186 & -0.206 & 1.000 & \\
\hline $\mathrm{Pb}$ & -0.061 & $0.220^{b}$ & $0.522^{a}$ & $0.551^{a}$ & $0.587^{a}$ & $0.707^{a}$ & 0.023 & 1.000 & $0.587^{a}$ & -0.355 & $0.717^{a}$ & $0.620^{a}$ & $0.675^{a}$ & $0.642^{a}$ & -0.148 & 1.000 \\
\hline
\end{tabular}

${ }^{a}$ Correlation is significant at the 0.01 level (2-tailed). ${ }^{b}$ Correlation is significant at the 0.05 level (2-tailed). 
Table 4 Correlations of trace metals contents with the altitudes, latitudes and longitudes of the sampling sites

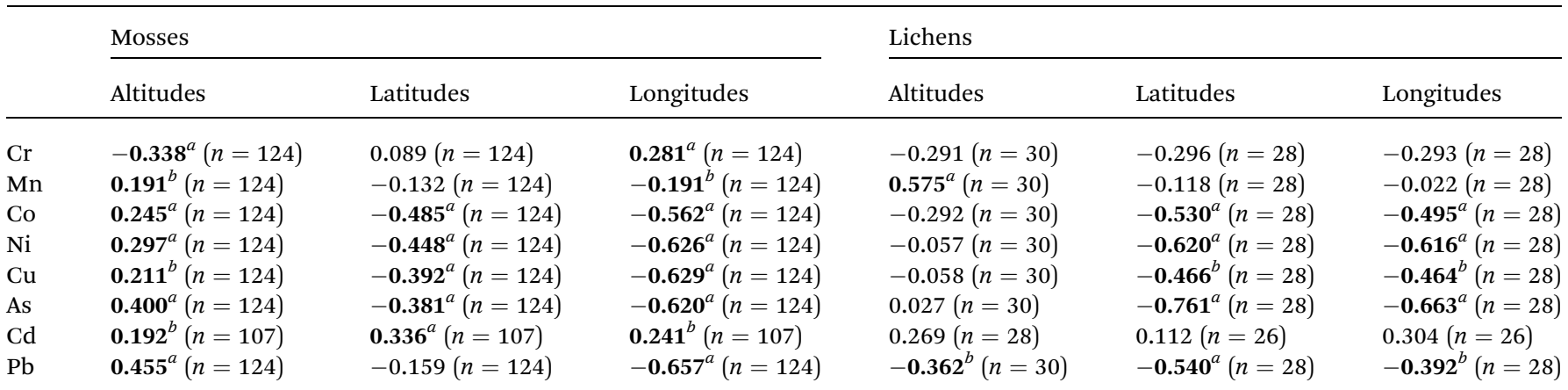

${ }^{a}$ Correlation is significant at the 0.01 level (2-tailed). ${ }^{b}$ Correlation is significant at the 0.05 level (2-tailed).

$C_{\text {normalized }}=($ absolute concentration of a metal $\times 100) /$ total concentration of all metals

The plots of PCA are presented in Fig. 3. For mosses, the first two principal components accounted for $83.1 \%$ of the total variance. The first principal component (PC1) explained 70.6\% of the total variance and was loaded highly by $\mathrm{Ni}, \mathrm{Co}, \mathrm{Mn}, \mathrm{Pb}$, As, $\mathrm{Cu}$ and $\mathrm{Cr}(0.956,0.953,-0.932,0.872,0.855,0.850,0.824)$. The second principal component (PC2) accounted for $12.5 \%$ of the total variance and loaded highly by Cd (0.954). For lichens, the first two principal components accounted for $87.0 \%$ of the total variance. The PC1 explained $71.4 \%$ of the total variance and was loaded highly by $\mathrm{Ni}, \mathrm{Co}, \mathrm{Mn}, \mathrm{Pb}, \mathrm{As}, \mathrm{Cu}$ and $\mathrm{Cr}(0.958$, $0.934,-0.915,0.919,0.867,0.927,0.734)$. The PC2 accounted for $15.6 \%$ of the total variance and loaded highly by Cd (0.817). These results indicated that the trace metals had a similar distribution patterns in mosses and lichens, although they had different accumulation ability for trace metals.

\subsection{Altitudinal and spatial distribution}

The correlations between the trace metals concentrations and the altitudes of the sampling sites were analyzed. Because of the feature of attaching to the trees, the distributions of lichens along with altitudes were limited to low altitude area where trees can grow. Thus, the correlations between most trace metals contents in lichens and the altitudes of the sampling sites were not significant. On the contrary, the concentrations of Mn, Co, $\mathrm{Ni}, \mathrm{Cu}, \mathrm{As}, \mathrm{Cd}$ and $\mathrm{Pb}$ in mosses had significantly positive correlation $(p<0.05)$ (Table 4$)$ with the altitudes of the sampling sites. With the ascending altitudes, the concentrations of $\mathrm{Mn}$, $\mathrm{Co}, \mathrm{Ni}, \mathrm{Cu}, \mathrm{As}, \mathrm{Cd}$ and $\mathrm{Pb}$ in mosses increased linearly. Higher precipitation and lower temperature could be mainly responsible for the higher concentrations in higher altitudes. ${ }^{29-31}$ Precipitation occurred more frequently in higher altitudes, resulting in greater wet deposition of pollutants. The scavenging ratio $(W)$ is defined as the ratio of an element or compound concentration in precipitation to its concentration in air to quantify the scavenging capacity of wet deposition. Theoretically, $W$ is a function of inverse temperature. Hence, $W$ value is relatively high in high-altitude area where temperature declined with increasing altitude. Thus, the pollutants appeared high concentrations in high altitudes areas.

In this work, the correlations between the contents of trace metals in mosses and lichens and the latitudes and longitudes of the sampling sites were executed to identify the possible source region of these trace metals in the Tibetan Plateau (Table 4). In both mosses and lichens, the concentrations of $\mathrm{Co}, \mathrm{Ni}, \mathrm{Cu}$ and As had significantly negative correlation $(p<0.05)$ with the latitudes and longitudes of the sampling sites. These negative correlations reflected the contents of these trace metals in mosses and lichens decreased from south to north and from west to east, indicating the possible source region of $\mathrm{Co}, \mathrm{Ni}, \mathrm{Cu}$ and As was South Asia. ${ }^{12,13}$

\section{Conclusion}

The profiles and distributions of trace metals in mosses and lichens in a large scale from the Tibetan Plateau were studied. Both mosses and lichens in the studied area had higher levels of trace metals than those from the Antarctic and Arctic. Mosses and lichens from the Tibetan Plateau had different accumulation efficiency for $\mathrm{Cr}, \mathrm{Mn}, \mathrm{Co}, \mathrm{Ni}, \mathrm{Cu}$, As and $\mathrm{Pb}$. The concentrations of $\mathrm{Mn}, \mathrm{Co}, \mathrm{Ni}, \mathrm{Cu}, \mathrm{As}, \mathrm{Cd}$ and $\mathrm{Pb}$ in mosses increased linearly with the altitudes of the sampling sites, implying the mountain trapping of the high-altitude Tibetan Plateau to these trace metals.

\section{Acknowledgements}

The work described here was supported by the National Basic Research Program of China (2013CB430004, 2014CB460612), the National Natural Science Foundation of China (41422306 and 21120102040) and the Young Scientists Fund of Research Center for Eco-Environmental Sciences (RCEES-QN-20130007F).

\section{References}

1 R. Q. Yang, S. J. Zhang, A. Li, G. B. Jiang and C. Y. Jing, Environ. Sci. Technol., 2013, 47, 12736-12743.

2 M. Loewen, S. C. Kang, D. Armstrong, Q. G. Zhang, G. Tomy and F. Y. Wang, Environ. Sci. Technol., 2007, 41, 7632-7638. 
3 X. Huang, M. Sillanpää, E. T. Gjessing and R. D. Vogt, Sci. Total Environ., 2009, 407, 6242-6254.

4 X. D. Liu and B. D. Chen, Int. J. Climatol., 2000, 20, 17291742.

5 G. D. Cheng and T. H. Wu, J. Geophys. Res.: Earth Surf., 2007, 112, F02S03.

6 C. Q. Yu, Y. J. Zhang, H. Claus, R. Zeng, X. Z. Zhang and J. S. Wang, Environ. Sci. Technol., 2012, 46, 1979-1980.

7 N. L. Zhu, J. J. Fu, Y. Gao, P. Ssebugere, Y. W. Wang and G. B. Jiang, Environ. Pollut., 2013, 181, 7-13.

8 R. Q. Yang, T. D. Yao, B. Q. Xu, G. B. Jiang and X. D. Xin, Environ. Int., 2007, 33, 151-156.

9 Q. G. Zhang, K. Pan, S. C. Kang, A. Zhu and W. X. Wang, Environ. Sci. Technol., 2014, 48, 5220-5228.

10 X. P. Zhang, W. Deng and X. M. Yang, J. Asian Earth Sci., 2002, 21, 167-174.

11 X. W. Fu, X. B. Feng, W. Z. Zhu, S. F. Wang and J. L. Lu, Atmos. Environ., 2008, 42, 970-979.

12 Z. Y. Cong, S. C. Kang, X. D. Liu and G. F. Wang, Atmos. Environ., 2007, 41, 1180-1187.

13 H. Z. Yuan, E. F. Liu, J. Shen, H. J. Zhou, Q. F. Geng and S. Q. An, J. Geochem. Explor., 2014, 136, 76-83.

14 R. Bargagli, F. Monaci, F. Borghini, F. Bravi and C. Agnorelli, Environ. Pollut., 2002, 116, 279-287.

15 T. Berg and E. Steinnes, Sci. Total Environ., 1997, 208, 197206.

16 T. Berg and E. Steinnes, Environ. Pollut., 1997, 98, 61-71.

17 S. Loppi and I. Bonini, Chemosphere, 2000, 41, 1333-1336.

18 P. C. Onianwa, Environ. Monit. Assess., 2001, 71, 13-50.
19 R. Bargagli, D. H. Brown and L. Nelli, Environ. Pollut., 1995, 89, 169-175.

20 S. Grangeon, S. Guedron, J. Asta, G. Sarret and L. Charlet, Ecol. Indic., 2012, 13, 178-183.

21 E. D. Wannaz, H. A. Carreras, C. A. Perez and M. L. Pignata, Sci. Total Environ., 2006, 361, 267-278.

22 S. M. Allen-Gil, J. Ford, B. K. Lasorsa, M. Monetti, T. Vlasova and D. H. Landers, Sci. Total Environ., 2003, 301, 119-138.

23 J. Chiarenzelli, L. Aspler, C. Dunn, B. Cousens, D. Ozarko and K. Powis, Appl. Geochem., 2001, 16, 245-270.

24 R. Bargagli, J. C. Sanchez-Hernandez and F. Monaci, Chemosphere, 1999, 38, 475-487.

25 P. Adamo, S. Giordano, S. Vingiani, R. C. Cobianchi and P. Violante, Environ. Pollut., 2003, 122, 91-103.

26 C. J. Saitanis, M. V. Frontasyeva, E. Steinnes, M. W. Palmer, T. M. Ostrovnaya and S. F. Gundorina, Environ. Monit. Assess., 2013, 185, 955-968.

27 M. Mohan, M. Deepa, E. V. Ramasamy and A. P. Thomas, Environ. Monit. Assess., 2012, 184, 4233-4245.

28 M. Nair, K. V. Jayalakshmy, K. K. Balachandran and T. Joseph, Environ. Forensics, 2006, 7, 197-206.

29 X. W. Fu, X. B. Feng, W. Z. Zhu, S. Rothenberg, H. Yao and H. Zhang, Environ. Pollut., 2010, 158, 2324-2333.

30 C. Stankwitz, J. M. Kaste and A. J. Friedland, Environ. Sci. Technol., 2012, 46, 8061-8068.

31 H. Zhang, R. S. Yin, X. B. Feng, J. Sommar, C. W. N. Anderson, A. Sapkota, X. W. Fu and T. Larssen, Sci. Rep., 2013, 3, 1-8. 